to $c$ modulo $H$ which are less than $x$ for which $G(t)$ has all of its prime factors greater than $x^{1 / R}$, i.e., $G(t)$ has at most $R \cdot m$ prime factors, $m$ being the degree of the polynomial. Since the polynomial $F(n)$ of Theorem 1 is equal to $F(c) G(t)$, the theorem follows if we set

$$
A=R m+A_{1},
$$

where $A_{1}$ is the number of prime factors of $F(c)$.

\title{
References
}

[1] V. Brun, Le crible d'Eratosthene et le theoreme de Goldbach, Norske Videnskapselskapets Skripter I. Kristiania, 3 (1920).

[2] E. Landau, Elementary Number Theory, Chelsea, New York, 1958.

[3] R. Miech, Almost primes generated by a polynomial, Acta Arith. 10 (1964), pp. $11-32$.

[4] K. Prachar, Primzahlverteilung, Berlin-Gottingen-Heidelberg 1957.

[5] A. Renji, On the representation of an even number as the sum of a prime and of an almost prime. American Mathematical Society Translations, Ser. 2, Vol. 19, Amer. Math. Soc., Providence, R. I., 1962. (English). Izvestiya Akad. Nauk SSSR. Ser. Mat. 12 (1948), pp. 57-78 (Russian).

UNIVERSITY OF ILLINOIS

URBANA, ILLTNOIS

Reçu par la Rédaction le 20.3.1964

\section{On Mordell's theorem}

br

I. SH. SLAVtTSKY (Leningrad)

1. Suppose that $R(1 \bar{d})$ is a real quadratic field with fundamental discriminant $d$, main unit $E_{1}=T_{1}+C_{1} \sqrt{d}$ and class number $h(\bar{d})$. Following Berger and Leopoldt $([6],[21])$, we introduce the generalized Bernoulli numbers $B_{x}^{k}$ belonging to a primitive residue character $\chi$ modulo $f \geqslant 1$ by the relation( $\left.{ }^{1}\right)$

$$
\sum_{r=1}^{j} \frac{\chi(r) t e^{r t}}{e^{j t}-1}=\sum_{k=0}^{\infty} B_{z}^{k} \frac{t^{k}}{k !}, \quad|t|<\frac{2 \pi}{f} .
$$

Then the results we find in some Mordell's articles ([24]-[27]), and in the article by Ankeny and Chowla ([4]) demonstrate the equivalence of two facts

$$
\begin{aligned}
C_{1} & \equiv 0(\bmod p), \\
B_{z}^{(p-1) 2} & \equiv 0(\bmod p),
\end{aligned}
$$

where $f=1$ for $d=p \equiv 1(\bmod 4)$, and $f=4$ for $d=4 p, p \equiv 3(\bmod 4)$.

This fact was first stated by Kiseler ([15], [16]) and later independently by Ankeny, Artin and Chowla ([1], [2], [4]), but Mordell succeeded without Dirichlet's formulae which have not up to now been proved with the help of elementary methods.

In this note, by extending Mordell's method of $p$-adic logarithm, there is demonstrated the

THEOREM. Let $R(\sqrt{\bar{d}})$ be a real quadratic field with fundamental discriminant $d=n p, p>3$, an odd prime number and $1 \leqslant n<p$. The congruence

$$
U_{1} \equiv 0\left(\bmod p^{7}\right)
$$

(1) As for arithmetical properties of $B_{z}^{k}$, see articles [9], [18], [19], [21], [29] We remark also that for $f=1$ and $f=4$, generalized Bernoulli numbers correspond to usual Bernoulli and Euler numbers. 
holds if and only if

$$
\frac{1}{m} B_{z}^{m} \equiv 0\left(\bmod p^{l}\right)
$$

where $l$ is any positive integer, $m=((p-1) / 2) p^{l-1}, \varepsilon=(-1)^{(p-1) / 2}$ and $z(x)=\left(\frac{\varepsilon n}{x}\right)$ is Kronecker's symbol.

The demonstration is obtained with the help of an estimate for the class number $h(d)$

2. It is known that $h(d)=O(\sqrt{d})$ and a more exact result follows from Hardy-Littlewood's hypothesis ([3])

$$
h(d)=O\left(\sqrt{d} \frac{\ln \ln d}{\ln d}\right) .
$$

Also for any $\varepsilon>0$ there exists infinitely many real quadratic fields such that $h(d)>d^{1 / 2-\varepsilon}$ (see [5]).

For the purpose of our note, for example, the following estimate is sufficient $\left({ }^{2}\right)$

$$
h(d)<\sqrt{d}
$$

This specification of the result of Polya ([18]), Schur ([32]), Landau ([20]) and Hua Loo Ken ([12]) can be easily derived if we consider Dirichlet's formulae for class number of real quadratic field in the form

$$
h(d)=\frac{\sqrt{d}}{2 \ln E_{1}} \mathscr{L}(1 \mid \chi)
$$

where $\mathscr{L}(1 \mid \chi)=\sum_{n=1}^{\infty} \frac{\chi(n)}{n}$ and $\chi(n)=\left(\frac{d}{n}\right)$ is Kronecker's symbol.

Indeed for $E_{1}=\frac{1}{2}(t+u \sqrt{d})$ provided $t^{2}-u^{2} d= \pm 4$ the inequality $t \geqslant u \sqrt{d-4}$ holds, so that

$$
E_{1}>\frac{1}{2} u(\sqrt{\bar{d}}+\sqrt{d-4})>\sqrt{d-3},
$$

and since $\mathscr{L}(1 \mid \chi)<\frac{1}{2} \ln d+1$ (see [12], lemma 5), then

$$
h(d)<\sqrt{d} \frac{\frac{1}{2} \ln d+1}{\ln (d-3)} .
$$

$\left({ }^{2}\right)$ Note that many recent articles ([3], [8], [11], [22]) contain much weaker esults given sometimes for special cases. As for $d<-4$ we can get $h(d)<\frac{1}{3} \sqrt{|d|} \ln |d|$.
Inequality (3) follows since $\left(\frac{1}{2} \ln d+1\right) / \ln (d-3)<1$ for $d \geqslant 17$ and for $d=\bar{b}, 8,12,13$, as known, $h(d)=1$. Therefore $(3)$ is true for all $d$.

5. Let $k=R(g)$ with $g=\exp (2-i p)$. where $p$ is an odd prime rational integer and $R$ is rational number field. Then provided $n \geqslant 1$ and $(n, p)=1$, we consider a field $K=k(\xi)=R(\xi)$, where $\vdots=\exp (2 \pi i n)$ and $\xi=\exp (2-i / \mu p)$. From the theorem of class field theory (for example, see $[35],(h .3$, par. 12), the odd prime ideal $1-g$ from field $k$ decomposes in $K$ into the product of different prime ideals so that if $\mathfrak{p}$, a prime ideal of $K$ and $p(1-\varrho)$, then $\mathfrak{p}(1-\varrho)$ and therefore together with $(1-q)^{p-1} p$, we have $\mathfrak{p}^{p-1} p$. Selecting an integer $x \in K$ with $\mathfrak{p} \pi$, we consider the $\pi$-adic algebraic integers $a, b \in K$ such that $a \equiv b \equiv 1$ (modp). For these numbers, we define the quotient

$$
f(a)=\frac{a^{p^{l}}-1}{p^{7}}
$$

Since the formulae

$$
a \equiv b\left(\bmod p^{l} \mathfrak{p}\right), \quad \text { and } \quad\left(a+p^{l} \pi \beta^{l^{\prime}} \equiv a^{l^{l}}+p^{2 l} \pi \gamma^{\prime}\left(\bmod p^{2 l} \mathfrak{p}\right),\right.
$$

where $\beta, \gamma$ are $x$-adic integers of $K$, imply that $f(a) \equiv f(b)\left(\bmod p^{l} \mathfrak{p}\right)$, so the quotient $f(a)$ is characterized by residues $\bmod p^{l} \mathfrak{p}$. This quotient has the properties of a logarithm $\left({ }^{3}\right)$, namely, if $a \equiv b \equiv 1(\operatorname{modp})$, then

1. $f(a b) \equiv f(a)+f(b)\left(\bmod p^{l} \mathfrak{p}\right)$, since

$\frac{(a b)^{\mu^{l}}-1}{p^{l}}=\frac{a^{p^{l}} b^{p^{l}}-a^{p^{l}}+a^{p^{l}}-1}{p^{l}}=a^{p^{l}} \frac{b^{p^{l}}-1}{p^{l}}+\frac{a^{p^{l}}-1}{p^{l}}, \quad a^{p^{l}} \equiv 1\left(\bmod p^{l} \mathfrak{p}\right)$,

- $\quad$ 2. $f\left(\frac{a}{b}\right) \equiv f(a)-f(b)\left(\bmod p^{l} \mathfrak{p}\right)$.

Using these two properties, we conclude that

3. if $a_{i} \equiv b_{i} \equiv 1(\bmod \mathfrak{p}), 1 \leqslant i \leqslant s$, and

$$
\prod_{i} a_{i}-\prod_{i} b_{i} \equiv 0\left(\bmod p^{l} \mathfrak{p}\right),
$$

then we hare

$$
\sum_{i=1}^{s} \frac{a_{i}^{\gamma^{l}}-b_{i}^{p^{l}}}{p^{7}} \equiv 0\left(\bmod p^{l} \mathfrak{p}\right)
$$

$\left({ }^{3}\right)$ For details concerning relation between $f(a)$ and $p$-adie logarithm for case $l=1$, see [2], and for any $l \geqslant 1$ [23], [29]. 
Indeed, from $\prod_{i} a_{i}-\prod_{i} b_{i} \equiv 0\left(\bmod p^{l} p\right)$, it follows that

$$
\prod_{i} \frac{a_{i}}{b_{i}} \equiv 1\left(\bmod p^{l} \mathfrak{p}\right)
$$

or

$$
\left(\prod_{i} \frac{a_{i}}{b_{i}}\right)^{p^{l}}=1+p^{2 l} \pi \gamma
$$

with some $\pi$-adic integer $\gamma \in K$, so that

$$
\frac{1}{p^{l}}\left\{\left(\prod_{i} \frac{a_{i}}{b_{i}}\right)^{p^{l}}-1\right\} \equiv 0\left(\bmod p^{l} \mathfrak{p}\right)
$$

and, together with properties 1 and 2 for $f(a)$, we obtain property 3 . Mordell himself uses his $p$-adic logarithm method only in the cases $n=1$ and $n=4$.

4. Supposing $d=n p$ is a fundamental discriminant of the real quadratic field $R(\sqrt{d})$ with $1 \leqslant n<p$, we conclude that $h(d)<p$ (see (3)). Firstly we assume that $n>1$. Then Dirichlet's formula for the classnumber $h(\bar{d})$ of field $R(\sqrt{d})$ may be written as

or

$$
E_{1}^{2 h}=\prod_{\left(\frac{a}{b}\right)=-1,0<b<d}\left(1-\xi^{b}\right)^{2},
$$

$$
E_{1}^{-2 h}=\prod_{\left(\frac{d}{a}\right)=+1,0<a<d}\left(1-\xi^{a}\right)^{2}
$$

where $\left(\frac{d}{r}\right)$ is Kronecker's symbol. Then since

and

$$
E_{1}^{-2}=\left(T_{1}-U_{1} \sqrt{d}\right)^{2}
$$

the conditions

$$
\bar{U}_{1} \equiv 0\left(\bmod p^{2}\right)
$$

and

$$
\frac{\prod_{b}\left(1-\xi^{b}\right)^{2}-\prod_{a}\left(1-\xi^{a}\right)^{2}}{2} \equiv 0\left(\bmod p^{l} \mathfrak{p}\right)
$$

follow one from the other. Here the prime ideal $\mathfrak{p}$ of $R(\xi)$ divides $(1-\varrho)$, $\varrho=\exp (2 \pi i / p)$.
Writing $\zeta=\exp (2 \pi i / n), \varepsilon=(-1)^{(p-1) / 2}$ and selecting for every $b$ with condition $\left(\frac{d}{b}\right)=-1$ two positive integers $\mu$ and $v$ by

$$
b \equiv \begin{cases}n \mu(\bmod p), & 0<\mu<p, \\ p v(\bmod n), & 0<v<n,\end{cases}
$$

so that

$$
\xi^{b}=\zeta^{v} Q^{\mu} \quad \text { and } \quad-1=\left(\frac{d}{b}\right)=\left(\frac{\varepsilon n}{b}\right)\left(\frac{\varepsilon p}{b}\right)=\varepsilon\left(\frac{\varepsilon n}{\nu}\right)\left(\frac{\varepsilon p}{\mu}\right),
$$

we obtain

$$
1-\xi^{b}=1-\zeta^{\mu} \varrho^{\mu}=\varrho^{\mu}-\zeta^{\mu} \varrho^{\mu}+1-\varrho^{\mu}=\varrho^{\mu}(1-\zeta)\left[1+\left(\varrho^{-\mu}-1\right)\left(1-\zeta^{\mu}\right)^{-1}\right] .
$$

Since $\left(\underline{o}^{\mu}, \mathfrak{p}\right)=(1-\zeta, \mathfrak{p})=1$ acting by analogy with $1-\xi^{a}$, where $\left(\frac{d}{a}\right)$ $=+1$, we rewrite $(8)$ in the form

$$
\begin{gathered}
\prod_{0<\mu<p, 0<p<n,\left(\frac{\varepsilon p}{\mu}\right)=-\varepsilon\left(\frac{e n}{v}\right)}\left[1+\left(Q^{-\mu}-1\right)\left(1-\xi^{\xi p}\right)^{-1}\right]^{2}- \\
-\prod_{0<\mu<p, 0<v<n,\left(\frac{e p}{\mu}\right)=\varepsilon\left(\frac{e n}{v}\right)}\left[1+\left(Q^{-\mu}-1\right)\left(1-\zeta^{\mu}\right)^{-1}\right]^{2} \equiv 0\left(\bmod p^{l} \mathfrak{p}\right) .
\end{gathered}
$$

Then using (5) and (6) we suppose that every product consists of $\varphi(d)$ numbers and cancelling by 2 we state

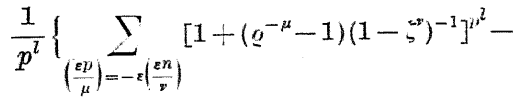

$$
\begin{aligned}
& \left.-\sum_{\left(\frac{\varepsilon p}{\mu}\right)=\varepsilon\left(\frac{\varepsilon p}{\nu}\right)}\left[1+\left(\varrho^{-\mu}-1\right)\left(1-\zeta^{-y}\right)^{-1}\right]^{p^{n}}\right\} \equiv 0\left(\bmod p^{z} \mathfrak{p}\right) .
\end{aligned}
$$

Further

$$
\begin{aligned}
& \frac{1}{p^{l}} \sum_{\substack{0<p<n \\
(p, n)=1}}\left\{\sum_{\substack{\left(\frac{p p}{u}\right)=-\varepsilon\left(\frac{\varepsilon n}{v}\right) \\
v}}\left[1+\left(Q^{-\mu}-1\right)\left(1-\xi^{-t}\right)^{-1}\right]^{p^{l}}-\right. \\
& \left.-\sum_{\left(\frac{\varepsilon p}{\mu}\right)=\varepsilon\left(\frac{\varepsilon n}{v}\right)}\left[1+\left(g^{-\mu}-1\right)\left(1-s^{-y}\right)^{-1}\right]^{p^{2}}\right\} \equiv 0\left(\bmod p^{2} \mathfrak{p}\right)
\end{aligned}
$$


or after raising to power and changing the order of summation,

$$
\text { (9) } \begin{aligned}
\sum_{k=1}^{p^{2}} \frac{1}{p^{l}} c_{p l}^{k l} \mid \sum_{v}\left(1-\zeta^{-1}\right)^{-k} & {\left[\sum_{\left(\frac{\varepsilon p}{\mu}\right)=-\varepsilon\left(\frac{\varepsilon n}{v}\right)}\left(\varrho^{-\mu}-1\right)^{k}-\right.} \\
& \left.\left.-\sum_{\left(\frac{\varepsilon p}{\mu}\right)=\varepsilon\left(\frac{n}{v}\right)}\left(\varrho^{\mu}-1\right)^{k}\right]\right\} \equiv 0\left(\bmod p^{l} \mathfrak{p}\right) .
\end{aligned}
$$

Note that

$$
\sum_{\left(\frac{\varepsilon p}{\mu}\right)=-\varepsilon\left(\frac{\varepsilon \mu}{\nu}\right)} Q^{-\mu i}=\left\{\begin{array}{l}
\frac{p-1}{2}, \quad \text { if } \quad p \mid i, \\
\frac{1}{2}\left[-1+\varepsilon\left(\frac{\varepsilon p}{\mu}\right)\left(\frac{\varepsilon p}{i}\right) \sqrt{\varepsilon p}\right], \quad \text { if } \quad p \nmid i,
\end{array}\right.
$$

and hence

$$
\begin{aligned}
& \sum_{\left(\frac{\varepsilon p}{\mu}\right)=-\varepsilon\left(\frac{\varepsilon i n}{\nu}\right)}\left(\varrho^{-\mu}-1\right)^{k}-\sum_{\left(\frac{\varepsilon p}{\mu}\right)=\varepsilon\left(\frac{\varepsilon n}{\nu}\right)}\left(\varrho^{-\mu}-1\right)^{k} \\
& =\frac{1}{2}\left(\frac{\varepsilon n}{\nu}\right) \sqrt{\varepsilon p} \sum_{i=0}^{k}(-1)^{k-i} C_{k}^{i}\left(\frac{\varepsilon p}{i}\right) .
\end{aligned}
$$

It is easy to see that

$$
\frac{1}{p^{l}} C_{p}^{k} C_{k}^{i}\left(\frac{\varepsilon p}{i}\right) \equiv(-1)^{k} \frac{1}{k} C_{k}^{i}\left(\frac{\varepsilon p}{i}\right)\left(\bmod p^{l}\right)
$$

since $\left(\frac{\varepsilon p}{i}\right)=0$, if $p \mid i$, and, if $p \nmid i$, then $\frac{1}{k} C_{k}^{i}$ is a $p$-adic integer. Then from (9)

$$
\sqrt{\varepsilon p} \sum_{k=1}^{p^{l}} \frac{(-1)^{k-1}}{k}\left\{\sum_{\nu}\left(\frac{\varepsilon n}{\nu}\right)\left(1-\zeta^{\nu}\right)^{-k} \sum_{i=0}^{k}(-1)^{k-i} C_{k}^{i}\left(\frac{\varepsilon p}{i}\right)\right\} \equiv 0\left(\bmod p^{l} \mathfrak{p}\right) .
$$

Since from all $i$ with $m=\frac{1}{2}(p-1) p^{l-1}$,

$$
\left(\frac{\varepsilon p}{i}\right) \equiv i^{m}\left(\bmod p^{l}\right)
$$

so $\sum_{i=0}^{k}(-1)^{k-i} C_{k}^{i}\left(\frac{\varepsilon p}{i}\right) \equiv \Delta^{k} 0^{m}\left(\bmod p^{l}\right)$, where $\Delta^{k} 0^{m}$ is a $k$-any finite difference.
Therefore

$$
-\sqrt{\varepsilon p} \sum_{k=1}^{p^{l}} \sum_{\nu} \frac{\left(\frac{\varepsilon n}{v}\right) \mathcal{A}^{k} 0^{n}}{k\left(s^{-v}-1\right)^{k}} \equiv 0\left(\bmod p^{l} \mathfrak{p}\right) .
$$

We notice that $1^{k} 0^{m}=0$ for $k>m$.

With the help of Kiseler's identity ([16], [17])

$$
\frac{1}{r} \sum_{r=1}^{r-1} B_{s}\left(\frac{r}{r}\right) \tau^{v^{t}}=\frac{(-1)^{s-1} s}{r^{s}} \sum_{k=1}^{s} \frac{f^{k} 0^{s}}{k\left(\tau^{r}-1\right)^{k}},
$$

where $r>1, v$ - integers, $0<v \leqslant r-1, \tau=\exp (2 \pi i / r)$ and $B_{s}(x)$ is a Bernoulli polynomial, we conclude from (10) that

$$
\frac{1}{m} \sum_{v}\left(\frac{\varepsilon n}{v}\right) \sum_{r=0}^{n-1} B_{m}\left(\frac{r}{n}\right){ }^{-r v} \equiv 0\left(\bmod p^{(p-1)\left(l-\frac{1}{2}\right)-1}\right) .
$$

Noticing that

$$
\sum_{v}\left(\frac{\varepsilon n}{v}\right) s^{-v v}=\left(\frac{\varepsilon n}{v}\right) \sqrt{1 \varepsilon n},
$$

we obtain at last

$$
\frac{1}{m} B_{z}^{m} \equiv 0\left(\bmod p^{(p-1)\left(l-\frac{1}{2}\right)+1}\right),
$$

where $\chi(v)=\left(\frac{\varepsilon n}{v}\right)$ is Kronecker's symbol and $B_{x}^{m}$ rational numbers, so. that

$$
\frac{1}{m} B_{x}^{n} \equiv 0\left(\bmod p^{l}\right) .
$$

In the case $d=p \equiv 1(\bmod 4)$, provided $\prod_{1 \leqslant r \leqslant p-1}(1-\vartheta)^{v}=p$ with $o=\exp (2 \pi i / p)$ we see that $C_{1} \equiv 0\left(\bmod p^{l}\right)$ is equivalent to

$$
\frac{\prod_{b}\left(1-\varrho^{b}\right)^{2}-\prod_{a}\left(1-\varrho^{a}\right)^{2}}{2} \equiv 0\left(\bmod p^{l+1} \mathfrak{p}\right) .
$$

Using the given abore method for $l^{\prime}=l+1$ and writing $m^{\prime}=((p-1) / 2) p^{l}$, finally from Kummer's congruence,

$$
\frac{B_{z}^{m^{\prime}}}{m^{\prime}} \equiv \frac{B_{z}^{m}}{m}\left(\bmod p^{l^{l}}\right)
$$

we get

$$
\frac{1}{m} B_{x}^{m} \equiv 0\left(\bmod p^{l}\right)
$$

where in this case $B_{z}^{m}=B_{m}$ are usual Bernoulli numbers. 
5. In connection with all said above, there is a hypothesis first suggested in the article [2], completed in [17] and repeatedly discussed in [33], [34], [19], [31]. Namely a far advanced calculation gives a right to suppose that in case when the discriminant of field $R(\sqrt{\bar{d}})$ is $d=p$ or $d=4 p$ ( $p \equiv 1, p \equiv 3(\bmod 4)$ respectively and $p$ an odd prime integer), we have

$$
U_{1} \not \equiv 0(\bmod p)
$$

or (just the same)

$$
B_{\chi}^{(p-1) / 2} \equiv 0(\bmod p) .
$$

Here $\chi$ is an character $\bmod f, f=1$ or 4 .

It is also interesting to observe that if $d<-4$, so for $d=-p$, $p \equiv 3(\bmod 4)$ and $d=-4 p, p \equiv 1(\bmod 4)$ (in both cases $p$ is an odd prime integer), we have( $\left.{ }^{4}\right)$

$$
h(d) \equiv-2 B_{z}^{(p+1) / 2}(\bmod p),
$$

where $\chi$ is a character $\bmod f, f=1$ or $4, \chi(-1)=-1$ for $f=4$.

Therefore since $h(d)<\frac{1}{3} \sqrt{|d|} \ln |d|$ for $d<-4$, in above cases we have $h(d)<p$ and thus

$$
B_{z}^{(p+1) / 2} \not \equiv 0(\bmod p) .
$$

Lastly we note that when the square free kernel of a composite discriminant contains more then one prime integer, this hypothesis is false. For example, for $d=184=8.23$, fundamental unit is $E_{1}=24335+$ $+897 \sqrt{184}$ and $U_{1}=897=29.23$

\section{References}

[1] N. S. Ankeny, E. Artin and S. Chowla, The class-number or real quadratic field, Proc. Nat. Acad. Sci. USA 37 (1951), pp. 524-525.

[2] - The class-number of real quadratic fields, Ann. of Math. 56 (1952) pp. $479-493$

[3] N.S. Ankeny and S. Chowla, $A$ note on the class-number of real quadratic field, Acta Arith. 6 (1960), pp. 145-147.

[4] - A further note on the class-number of real quadratic field, Acta Arith. 7 (1962), pp. $271-272$.

[5] N.S. Ankeny, R. Brauer and S. Chowla, A note of the class-numbers of algebraic number fields, Amer. Jour. of Math. 78 (1956), pp. 51-61.

[6] A. Berger, Recherches sur les nombres et les fonctions de Bernoulli, Acta Math. 14 (1890-1891), pp. 249 -304.

[7] L. Carlitz, The class-number of an imaginary quadratic field, Comm. Math. Helv. 27 (1953), pp. 338-345.

[8] - Note on the class-number of quadratic fields, Duke Math. Journ. 22 (1955), pp. 589-593.

(4) Congruence (11) first was indicated by Cauchy ([10]) and Hurwitz ([13]) See its generalization in [14] and [7].

[9] - Arithmetic properties of generalized Bernoulli numbers, Journ. für Math. 202 (1959), pp. $174-182$.

[10] A. L. Cauchr, Mémoire sur la théorie des nombres, note 4: Sur les résidues quadratiques, Oeuvres, 1 ser. 3 (1911), pp. 163-180.

[11] M. Gut, Abschätzungen für die Klassenzahlen der quadratischen Körper, Acta Arith. 8 (1963), pp. 111-122.

[12] L. K. Hua, On the least solution of Pell's equation, Bull. Amer. Math. Soc. 48 (1942), pp. $731-735$.

[13] A. Hurwitz, Über die Anzahl binarer quadratisehe Formen von negativer Determinante, Acta Math. 19 (1895), pp. 351-384.

[14] А. А. Fiпелев, Выражсение числа киассов идеалов квадратияных полей через числа Берну.и.и, Научная сессия Јенинградского Университета, Тезиси докладов по секции мат. наук, Тенинград 1948, pp. 37-39.

[15] А. A. Киселе в Быражение числа киассов идеа.ив вещественного квадратичного по.ля через чис.ла Берну.ли, ДАН СССР 61 (1948), рр.777-779.

[16] - O некоторых сравнениях для числа классов идеалов вещестеенны квадратичных полей, Учен. записки Тенннградского Университета, серия мат

[17] А. А. Киселев, И. ИІ. Славутский, $O$ иисле классов шелелов веществен ного квадратииного поля $и$ его колеч, ДАН СCCP 126 (1959), pp. 1191-1194.

[18] - - O некоторых сравнениях для ко.ииества представлений суммами нечетного числа квадратов, ДАН СССР 143 (1962), pp. 272-274.

[19] - - Преобразование бормул Дирихле и ариф.метическое өычисление числи клиссов идеалов квадратичных полей, Труды 4 Всесоюзного математического съезда, Јенинград 1961, Секционные доклады, 2 (1964), pp. 105.119.

[20] E. Landau, Abschätzungen von Charaktersummen, Einheit und Klassen$z a h l$, Nachr. Köng. Gesselsch. Wiss. Göttingen, Math.-Phys. Kl., 1 (1918), pp. 79-97. [21] H.-W. Leopoldt, Eine Verallgemeinerung der Bernoullischen Zahlen, Abh. Math. Seminar Univ. Hamburg 22 (1958), pp. $131-140$.

[22] - Über Klassenzahlprimteiler reeler Abelscher Zahlkörper als Primteiler erallgemeinerter Bernoullischer Zahlen, Abh. Math. Seminar Univ. Hamburg 23 , pp. $36-47$.

[23] - Zur Approximation des p-adisehen Logarithmus, Abh. Math. Seminar Univ. Hamburg 25 (1961), pp. $77-81$.

[24] L. J. Mordell, On a Pellian equation conjecture, Acta Arith. 6 (1960), pp. $137-144$.

[25] - Recent work in number theory, Scripta Math. 25 (1960), pp. 93-103. [26] - A Pellian equation conjecture, Second Hungarian Math. Congress 1960 , 1, Budapest, 1961, 1b, pp. 24-27.

[27] - A Pellian equation conjecture 2, Journ. Lond. Math. Soc. 36 (1961), pp. $282-288$.

[28] G. Polז̦a, Über die Ferteilung der quadratischen Reste und Nichreste, Nachr. Köng. Gesellsch. Wiss. Göttingen, Math.-Phy̧s. Kl., I (1918), pp. 79-97.

[29] II. ШI. Славутский, Арифметические свойства числа классов идеалов кеадратияных полей, Диссертадия, Јенинградский Университет, 1959.

[30] - Об ариф.метической структуре L-фуункций Iирих.ие, 8ая научная конференция Хабаровского педагогического пнститута, 1961, pp. 125-127.

[31] - O чис.ле к.лассов идеалов вещественного квадратичного по.ия с простьм оискриминантом, Ученые записки Јенинградского Педагогического института 218 (1961), pp. 179-189.

Acta Arithmetica $\mathrm{XI} .1$ 
[32] I. Schur, Einige Bemerkungen zu der vorstehender Arbeit des Herrn G. Polya „Über die Verteilung der quadratischen Reste und Nichreste", Nachr. Köng. Gesellsch. der Wiss. Göttingen, Math.-Phys. Kl. 1 (1918), pp. 30-36.

[33] O. Taussky, Some computational problems in algebraic number theory, Proc. Sxmp. Appl. Math., 6, Numerical Anal., New York 1956, pp. 187-193.

[34] O. Taussky and J. Todd, Some discrete variable computations, Proc. Symp. Appl. Math., New York, 10 (1960), pp. $201-209$.

[35] H. Weyl, Algebraic theory of numbers, 1940.

Reçu par la Rédaction le 11.5. 1964

\section{On the zeros of $L$-functions}

br

E. FogELs (Riga)

Introduction

1. Let $L(s, \chi)$ be any $L$-function of Dirichlet with a character $\chi$ to modulus $D>2$. Csing an unproved hypothesis in 1945, Linnik prored (see [10], §1i) that for any $\lambda \in[0, \log D]$ and $t_{0} \in\left[-\log ^{3} D, \log ^{3} D\right]$ the number of zeros of $L(s, \gamma)$ lying in the rectangle $(1-\lambda / \log D \leqslant \sigma \leqslant 1$, $\left.t_{0} \leqslant t \leqslant t_{0}+1\right)$ in the plane of the complex rariable $s=\sigma+i t$ does not exceed $e^{c_{0}}$, where $c_{0}$ (and later on $c, c^{\prime}, c_{1}, c_{2}, \ldots$ ) stands for an appropriate absolute constant $>0\left(^{1}\right)$. In 1944 Linnik [9] proved by a very complicated method that the number of functions $L(s, \chi)$ having at least one zero in the rectangle $\left\{1-\lambda / \log D \leqslant \sigma \leqslant 1,|t| \leqslant \min \left(\lambda^{100}, \log ^{3} D\right)\right\}$ does not exceed $e^{c_{2} \lambda}$. Ten years later Rodosskii ([12], pp. 333-341) gave a simpler proof, but merely for the rectangles $(1-\lambda / \log D \leqslant \sigma \leqslant 1$, $\left.|t| \leqslant e^{\bar{\lambda}} / \log D\right)$. In 1961 Tuxán [13] proved by his new method a slightly more general result: The number of zeros of the function $Z(s)=I I L(s, \chi)$ in the rectangle $\left(1-\lambda / \log D \leqslant \sigma \leqslant 1,\left|t-t_{0}\right| \leqslant e^{\lambda} / \log D\right)$ with $\left|t_{0}\right|<D^{1 / 2}$ does not exceed $e^{c_{3} \lambda}$.

The height of the rectangle considered by Turán or Rodosskii for a large $D$ and $\lambda<\log \log \log D$ (for example) is very small. In order to eliminate this restriction I have combined Turán's method with some ideas taken from Linnik's paper [10]. By these means I have succeeded in proving the following

THEOREM. (i) For any $T \geqslant D$ and $\lambda \in[0, \log T]$ the number of zeros of the function $L(s, \chi)$ in the rectangle

$$
(1-\lambda \cdot \log T \leqslant \sigma \leqslant 1,|t| \leqslant T)
$$

does not exceed $e^{c \lambda}$

(ii) The same is true for the function $Z(s)=\prod_{\chi} L(s, \chi)$.

(1) Linnik's proof is based on the following hypothesis: Any circle of radius $1 / \log D$ with the centre in the rectangle $\left(1-\log \log D / \log D<\sigma<1,|t|<\log ^{3} D\right)$ contains no more than $c_{1}$ zeros of $L(s, \chi)$. He promised (see [10], pp. 111 and 118) to publish another proof for the case in which this hypothesis does not hold. Twenty years have elapsed since, but no proof of this kind has been published yet. 